\title{
Paediatric outpatient utilisation in a district general hospital
}

\author{
R MacFaul, R Long
}

\begin{abstract}
Paediatric outpatient utilisation in a district general hospital was studied for 20 general practices that covered a population of 26433 children. The actions taken by paediatric staff were analysed for 487 new referrals and 2784 review attendances (the latter in 1630 children) over an eight month period.

New referral rates from different general practices varied between 3.7 per thousand children 0 to 15 years and 29.6 with a mean of 13.7, equivalent to 19 per thousand per year. (The national mean based on health district populations is $\mathbf{2 1 . 2}$ per year.) A total of $63 \%$ of new referrals and $49 \%$ of review patients were aged under 5 years. Over the study period $2.2 \%$ of children under 5 years in the population were referred as a new patient, equivalent to $3.1 \%$ per year, and $1.3 \%$ of children aged 0 to 15 years were referred, equivalent to $1.8 \%$ per year. Review attendances on one or more occasion occurred in $6.5 \%$ of children under 5 years over the study period, equivalent to $9.2 \%$ per year, and for age 0 to 15 years, $4.8 \%$ attended once or more times over the study period, equivalent to $6.7 \%$ per year. The review attendance rate per thousand child population per practice varied between 59 and 160 with a mean of 81.9 . New patients formed $14.8 \%$ of the total attendances (the national mean is $18.3 \%$ ).
\end{abstract}

Review attendance rates were significantly lower when the general practice was large. Socioeconomic factors suggested by a high proportion of children in the general practice list were associated with a high review attendance rate. Altogether $\mathbf{2 7 . 0 \%}$ of new referrals were seen once only and $32.8 \%$ had no tests done. The most common reason for attendance was asthma (11\% of new and $19 \%$ of review patients). The second commonest was for fits $(8.4 \%$ of new referrals and $4.7 \%$ of review patient attendances).

(Arch Dis Child 1992;67:1068-72)

Departments of Paediatrics and Information, Pinderfields General Hospital Aberford Road, Wakefield, West Yorkshire WF1 4DG R MacFaul $\mathbf{R}$ Long Correspondence to: Dr MacFaul.

Accepted 28 April 1992 outpatient service in the NHS and mostly this is numerical data for health service indicators (HSIs) based on district health authority populations. Information has been published on new referral of children to hospital outpatient clinics for all specialties-rather than just paediatric outpatient clinics - and has been documented at a rate of 100 referrals per thousand children aged 0 to 4 years and $64 \cdot 3$ per thousand children aged 5 to 14 per year. 'In a review of 1093 children aged 3.5 years forming part of the British births study, $4 \%$ had attended a paediatric outpatient clinic one or more times in their lives (excluding neonatal follow up clinic attendance). ${ }^{2}$ Variations between districts may partly be related to measures of socioeconomic deprivation. ${ }^{3}$ Considerably more information is available upon the use of inpatient hospital services and also of child health clinics. ${ }^{4-6}$

\section{Methods}

This study was based on a larger paediatric outpatient audit project. In this project, a form was prepared for each patient by an audit clerk that was completed by the doctor seeing the child. Diagnoses were coded using Read coding and actions taken in the clinic such as further appointment, referral to imaging, pharmacy, pathology, therapists, etc were recorded and analysed in respect of grade of staff and related to the case mix. The details of the referring general practice and the postcode of residence of the patient provided the data reported in this paper.

Over the period of the study between 4 September 1989 and 10 May $1990(0.71$ of a year), 487 new patients were seen and 2784 review attendances occurred in 1630 children.

Review attendances followed a previous outpatient attendance or were for follow up after an inpatient admission, the latter amounting to 9.5\% of the review attendances. Excluded from the study were ward attenders and newborn babies reviewed in the maternity hospital.

The majority of the patients, $69 \%$, came from Wakefield and $31 \%$ came from the Leeds, Pontefract, Dewsbury, or Barnsley district health authority populations.

Detailed analysis was made of new referral and review attendance from the Wakefield general practices as the population data available showed that these 20 general practices represented $97 \%$ of the Wakefield district health authority population ( $93 \%$ for 0 to 15 years) and child population data were available for these practices. The analysis therefore is based on $69 \%$ of the outpatient attendances (see tables and 2 and results section (c)).

\section{Results}

\section{(A) NEW REFERRALS}

Although the majority $(87 \%)$ of new referrals were from the general practitioner (GP), there were 26 , with prior agreement of the GP, from doctors working in the community child health service and a further eight referrals were made 
Table 1 Population summary

\begin{tabular}{lll}
\hline & $\begin{array}{l}\text { Total } \\
\text { No }\end{array}$ & $\begin{array}{l}0 \text { to } \\
15 \text { years }\end{array}$ \\
\hline $\begin{array}{ll}\text { Wakefield DHA* } \\
\text { Wakefield DHA practicest }\end{array}$ & 145820 & 28520 \\
$\begin{array}{l}\text { Catchment population: } \\
\text { All acute specialties }\end{array}$ & 141048 & 26433 \\
Paediatrics & 209000 & 46460 \\
\hline Source: ${ }^{*}$ HSIs; †Family Health Services Authority. \\
DHA=district health authority.
\end{tabular}

Table 2 Outpatient attendances

\begin{tabular}{lll}
\hline & $\begin{array}{l}\text { New } \\
\text { referrals }\end{array}$ & $\begin{array}{l}\text { Review } \\
\text { attendances }\end{array}$ \\
\hline $\begin{array}{l}\text { Total in outpatient study } \\
\text { Wakefield DHA practices (\%) }\end{array}$ & $\begin{array}{l}487 \\
336(69)\end{array}$ & $\begin{array}{l}2784 \\
1922(69)\end{array}$ \\
\hline DHA = district health authority. & &
\end{tabular}

Table 3 New patient referrals: the most common reasons/ diagnoses by Read code groups representing 290 (59.5\%) of the total 487 new referrals

\begin{tabular}{|c|c|c|}
\hline Diagnosis & Read code & No $(\%)$ \\
\hline Asthma/wheezing & $\begin{array}{l}\text { H33 } \\
\text { R060 }\end{array}$ & $57(11 \cdot 7)$ \\
\hline Fits? (epilepsy in 17) & $\begin{array}{l}\text { F25+ } \\
\text { R002 and } 3\end{array}$ & $41(8 \cdot 4)$ \\
\hline Headaches (migraine in 18) & $\begin{array}{l}\text { F26 } \\
\text { R040 }\end{array}$ & $29(5 \cdot 9)$ \\
\hline $\begin{array}{l}\text { Cardiac murmur (significant } \\
\text { in four) }\end{array}$ & $\begin{array}{l}\text { G54Z } \\
\text { P code } \\
\text { R052+ }\end{array}$ & $28(5 \cdot 7)$ \\
\hline $\begin{array}{l}\text { Behaviour disorder (excluding } \\
\text { enuresis/soiling) }\end{array}$ & $\begin{array}{l}\text { E272 } \\
\text { E274 } \\
\text { E2C and D } \\
\text { ECZ+ }\end{array}$ & $19(3 \cdot 9)$ \\
\hline $\begin{array}{l}\text { Urinary tract infection } \\
\text { Chronic diarrhoea }\end{array}$ & $\begin{array}{l}\text { K190 } \\
\text { A08ZZ } \\
\text { R0772 } \\
\text { J525 }\end{array}$ & $\begin{array}{l}19(3.9) \\
16(3 \cdot 3)\end{array}$ \\
\hline $\begin{array}{l}\text { Short stature } \\
\text { Abdominal pain }\end{array}$ & $\begin{array}{l}\text { R0345 } \\
\text { R090+ } \\
\text { J521 }\end{array}$ & $\begin{array}{l}16(3 \cdot 3) \\
15(3 \cdot 1)\end{array}$ \\
\hline Constipation/soiling & $\begin{array}{l}\text { PB2 } \\
\text { J520 } \\
\text { E277 }\end{array}$ & $15(3 \cdot 1)$ \\
\hline Failure to thrive & $\begin{array}{l}\text { R0341 } \\
\text { R0342 } \\
\text { R0343 }\end{array}$ & $13(2 \cdot 7)$ \\
\hline $\begin{array}{l}\text { Recurrent upper respiratory } \\
\text { infections }\end{array}$ & $\begin{array}{l}\mathrm{H} 00 \\
\mathrm{H} 05 \mathrm{Z}\end{array}$ & $12(2 \cdot 5)$ \\
\hline Vomiting? reflux & $\begin{array}{l}\text { J1011 } \\
\text { R0701 and } 2\end{array}$ & $10(2 \cdot 1)$ \\
\hline Other & & $197(40 \cdot 5)$ \\
\hline Total & & $487(100 \cdot 1)$ \\
\hline
\end{tabular}

Table 4 Outpatients seen related to practice and to practice size aged 0 to 15 years (20 practices)

\begin{tabular}{|c|c|c|c|c|}
\hline \multirow{2}{*}{$\begin{array}{l}\text { No (\%) in practice } \\
\text { population aged } 0-15 \text { years }\end{array}$} & \multicolumn{2}{|c|}{ New referrals } & \multicolumn{2}{|c|}{ Review attendances } \\
\hline & No & $\begin{array}{l}\text { No/1000 aged } \\
0-15 \text { years }\end{array}$ & $\overline{N o}$ & $\begin{array}{l}\text { No/1000 aged } \\
0-15 \text { years }\end{array}$ \\
\hline $\begin{array}{l}2419(20 \cdot 6) \\
2414(21 \cdot 4) \\
2150(18 \cdot 5) \\
2038(17 \cdot 1) \\
2030(18 \cdot 3) \\
1906(20 \cdot 2) \\
1901(17 \cdot 5) \\
1526(16 \cdot 6) \\
1478(19 \cdot 9) \\
1439(17 \cdot 2) \\
1298(22 \cdot 5) \\
1124(19 \cdot 3) \\
1082(15 \cdot 9) \\
809(15 \cdot 8) \\
753(18 \cdot 8) \\
570(22 \cdot 5) \\
509(15 \cdot 4) \\
430(21 \cdot 9) \\
357(14 \cdot 9) \\
200(49)\end{array}$ & $\begin{array}{r}34 \\
18 \\
19 \\
44 \\
26 \\
23 \\
19 \\
7 \\
14 \\
26 \\
14 \\
10 \\
32 \\
3 \\
8 \\
11 \\
7 \\
9 \\
8 \\
4\end{array}$ & $\begin{array}{c}14 \cdot 1 \\
7 \cdot 5 \\
8 \cdot 8 \\
21 \cdot 6 \\
12 \cdot 8 \\
12 \cdot 1 \\
10 \\
4 \cdot 5 \\
9 \cdot 5 \\
18 \cdot 1 \\
10 \cdot 8 \\
8 \cdot 9 \\
29 \cdot 6 \\
3 \cdot 7 \\
10 \cdot 6 \\
19 \cdot 3 \\
13 \cdot 7 \\
21 \\
18 \cdot 7 \\
20\end{array}$ & $\begin{array}{r}145 \\
134 \\
110 \\
195 \\
142 \\
117 \\
113 \\
164 \\
109 \\
124 \\
87 \\
38 \\
105 \\
46 \\
64 \\
51 \\
41 \\
69 \\
33 \\
35\end{array}$ & $\begin{array}{c}59 \cdot 9 \\
55 \cdot 5 \\
51 \cdot 2 \\
95 \cdot 7 \\
70 \\
61 \cdot 4 \\
59 \\
105 \cdot 1 \\
73 \cdot 7 \\
86 \cdot 2 \\
67 \\
33 \cdot 8 \\
97 \\
56 \cdot 9 \\
85 \\
89 \\
80 \\
160 \\
77 \cdot 3 \\
175\end{array}$ \\
\hline $\begin{array}{l}\text { Total } 26433 \\
\text { Mean }\end{array}$ & 336 & $13 \cdot 7$ & 1922 & $81 \cdot 9$ \\
\hline
\end{tabular}

at the instigation of the community doctors. Thus $7 \%$ of all new referrals arose from community child health doctors.

\section{(B) MOST COMMON DIAGNOSES IN NEW} REFERRALS

These are given in table 3 and the variable diagnostic coding for similar disorders used in the study are illustrated. There is a need to use groups of Read codes when searching for similar disorders.

\section{(C) REFERRAL PATTERNS FOR GENERAL \\ PRACTICES}

The pattern of new referral and review attendances based upon each of the Wakefield district health authority practices is shown in table 4. Detailed analysis was made of new referral rates and review attendance rates per thousand children aged 0 to 15 years according to general practice characteristics: (a) size of general practice child population and (b) the proportion of the general practice list who were in this age band.

\section{(i) GP new referral rates}

The number of new outpatient referrals related closely to the size of the practice and the new referral rate per thousand child population 0 to 15 years from each general practice had a mean (SD) of $13.7(6.5)$ per thousand over 0.71 of a year (equivalent to 19 per thousand over a year). The referral rate of new outpatients per thousand was not significantly related to general practice size or proportion of practice list who were children.

\section{(ii) Review attendances by general practice}

Predictably, the greater the size of the practice, the greater the number of review patients seen. The review attendance rate per thousand child population aged 0 to 15 years, however, varied between 33.8 and 175 with a mean (SD) of 81.9 $(34 \cdot 2)$, equivalent to $115 \cdot 3$ per year. The review attendance rate per thousand practice child population was greater when there was a higher than average proportion of the total practice list who were children $(r=0.6153, \mathrm{p}=0.004)$ but the review attendance rate per thousand was smaller the larger the size of the general practice population $(r=-0.5, p=0.013)$. The observation that larger general practices had lower review attendance rates may imply that bigger general practices are more able to undertake review of complex or serious disorders, perhaps by having a partner with a particular interest in paediatrics. The higher review attendance from the practices with a high proportion of children on their list may be a reflection of socioeconomic disadvantages in the population served.

These observations were also reflected in attendance patterns for asthma, but not for failure to thrive, which may be more closely linked to socioeconomic deprivation.

(D) DIAGNOSTIC CASE MIX

(i) The diagnostic coding made on new referrals 
Table 5 HSIs 1989 paediatrics group ranking: selected paediatric outpatient indicators

\begin{tabular}{|c|c|c|c|c|}
\hline Indictor & National mean & Wakefield value & Centile rank & In top $20 \%$ ? \\
\hline \multirow{4}{*}{$\begin{array}{l}\text { CL67 (outpatient referral } \\
\text { attendances } 1000 \\
\text { catchment population) } \\
\text { CL65 (outpatient average } \\
\text { referral attendances/clinic) } \\
\text { CL63 (\% of all attendances } \\
\text { that are referral } \\
\text { attendances) } \\
\text { MS21 (consultants/10 000 } \\
\text { referrals seen) }\end{array}$} & $21 \cdot 2$ & $28 \cdot 4$ & 88 & Yes \\
\hline & $2 \cdot 02$ & $3 \cdot 17$ & 94 & Yes \\
\hline & $18 \cdot 34$ & $22 \cdot 29$ & 82 & Yes \\
\hline & $32 \cdot 6$ & $22 \cdot 7$ & 22 & No \\
\hline
\end{tabular}

Source: Department of Health; HSIs 1989.

and review attendances has allowed further detailed analysis which will be reported separately ( $R$ MacFaul, $R$ Long, in preparation). It has also been possible to demonstrate the range of conditions seen by each consultant and by other grades of staff.

(ii) A HSI (CL-63, see table 5) gives the ratio of new outpatients in comparison to the total number seen for each health district, the national mean being $18 \cdot 34 \%$ for paediatrics and for Wakefield is shown as $22 \cdot 29 \%$. However, for this study the ratio was $\mathbf{1 4 \cdot 8 \%}$ and furthermore, data from this study enables the ratio to be

Table 6 Frequent review attenders: more than five attendances over the eight month period

\begin{tabular}{ll}
\hline Diagnosis & $\begin{array}{l}\text { No of } \\
\text { attendances }\end{array}$ \\
\hline Asthma & 40 \\
Epilepsy & 35 \\
Mental handicap with/without & \\
epilepsy or cerebral palsy & 31 \\
Arthritis & 17 \\
Cystic fibrosis & 16 \\
Failure to thrive & 16 \\
Idiopathic thrombocytopenic purpura & 12 \\
Diabetes & 10 \\
Constipation/soiling & 9 \\
Brucellosis (one child) & 8 \\
\hline
\end{tabular}

Table 7 Action taken by consultant

\begin{tabular}{ll}
\hline Consultant & $\begin{array}{l}\text { \% New patients } \\
\text { seen once only }\end{array}$ \\
\hline A & 18 \\
C & 36 \\
Total & 20 \\
\hline
\end{tabular}

Table $8 \%$ Follow up or discharge by staff grade

\begin{tabular}{lll}
\hline & $\begin{array}{l}\text { Further } \\
\text { appointment }\end{array}$ & Discharge \\
\hline Consultant & $77 \cdot 5$ & $20 \cdot 1$ \\
Clinical assistant & $83 \cdot 3$ & $15 \cdot 5$ \\
Experienced senior house officer & $84 \cdot 0$ & $15 \cdot 1$ \\
Senior house officer GPVTS & 81.5 & 17.5 \\
\hline *Genel practice vocational trainee.
\end{tabular}

Table $9 \%$ Paediatric outpatient utilisation arising from 20 general practices with a child population of 26433 children

\begin{tabular}{|c|c|c|c|c|}
\hline \multirow[t]{2}{*}{ Age } & \multicolumn{2}{|l|}{ New referrals } & \multicolumn{2}{|l|}{ Review attendances } \\
\hline & $\begin{array}{l}\text { Over period } \\
\text { of study }(0 \cdot 71 \text { year })\end{array}$ & $\begin{array}{l}\text { Per } \\
\text { year }\end{array}$ & $\begin{array}{l}\text { Over period } \\
\text { of study }(0 \cdot 71 \text { year })\end{array}$ & $\begin{array}{l}\text { Per } \\
\text { year }\end{array}$ \\
\hline $\begin{array}{l}0-5 \text { years } \\
0-15 \text { years }\end{array}$ & $\begin{array}{l}2 \cdot 2 \\
1 \cdot 3\end{array}$ & $\begin{array}{l}3 \cdot 1 \\
1 \cdot 8\end{array}$ & $\begin{array}{l}6 \cdot 5 \\
4 \cdot 8\end{array}$ & $\begin{array}{l}9 \cdot 2 \\
6 \cdot 7\end{array}$ \\
\hline
\end{tabular}

calculated separately for groups of children with differing diagnoses.

(iii) The most common reason for attending for review was asthma but the highest review attendance as a proportion of the total attendance for any specific condition was for diabetes as there were few new referrals for this disorder. A high proportion of review attendances (compared with new referrals) occurred when the review was for a condition that led the child to attend initially after an inpatient admission-for example, for febrile convulsion, meningitis or acute arthritis, and the child has not been referred as a new outpatient. Other conditions for which there was a high proportion of review attendances in relation to new referrals were mental handicap, cerebral palsy, and epilepsy.

These latter conditions also formed the largest number of review attendances, second only to asthma. Reviews after an inpatient admission were expected largely to have been seen by senior house officers, but were also seen by other grades of staff: consultants saw a third of these attendances.

(iv) Frequent review attendances-over the period of the study, 229 attendances were in children attending five times or more. The diagnoses for these children are summarised in table 6.

\section{(E) ACTIONS TAKEN IN CLINIC}

Actions taken by the consultant after a child was seen as a new patient were noted: $32 \cdot 8 \%$ had no investigations requested. Altogether $28 \%$ out of 487 new patients required no further follow up and the proportion varied between consultants (see table 7); $24 \%$ of new patients seen required neither investigation nor follow up.

Follow up appointments are initiated by the paediatric department rather than by the GP and consultants tended to discharge a higher percentage of the patients seen, although the difference between the consultant and the other grades of staff was minimal (see table 8); one explanation for this is that consultants were more likely to see children with chronic disorders who were less likely to be discharged.

\section{(F) PAEDIATRIC OUTPATIENT UTILISATION}

(i) Using the Wakefield district health authority general practice population the following figures were calculated: (a) of the new referrals, $63 \%$ were under 5 years of age and (b) of the review attendances, $49 \%$ were under 5 years of age.

(ii) Over the period of the study $(0 \cdot 71$ year) $2 \cdot 2 \%$ of 9070 children under 5 years of age from the Wakefield district health authority practice population of 141048 children of all ages were referred as new paediatric outpatients (equivalent to $3 \cdot 1 \%$ per year) and $6.5 \%$ of all those under 5 years attended once or more as review patients (equivalent to $9 \cdot 2 \%$ per year). For those aged 0 to 15 years these figures would be $1.8 \%$ and $6.7 \%$ per year respectively (based upon 1268 children who attended 1922 appoint- 
ments over 0.71 of a year); see table 9 . The HSIs for Wakefield are given in table 5 and allow comparison with the activities of other districts. The new patient referral rate per thousand on HSI-CL 67 appears high and exceptional. However, when analysis is based only on the Wakefield district health authority general practice population, the new referral rate is 13.7 per thousand 0 to 15 years over 0.71 of a year, equivalent to 19 per year and just below the national mean of $21 \cdot 2$. The remaining new referrals appearing on the HSIs are from cross boundary flow from other district health authorities where the population data are less clear. A small number of referrals for paediatric opinions may have been made from Wakefield general practices to other hospitals outside the district. Subsequent estimates, based on the contracting process, suggest that number is small and such referrals would lead to the rates in this report forming an underestimate of the demand for paediatric services.

The observed rate of referral in this study was therefore unlikely to have been unusually excessive and the paediatric outpatient utilisation figures are probably representative of national utilisation. This is the first study in the UK that provides such a population based measure of paediatric outpatient utilisation.

\section{Discussion}

This study has analysed GP new referrals and review attendance patterns based upon a known population size, providing some insight into utilisation of paediatric services. Of note is the high attendance of children under the age of 5 years $(63 \%$ of new attendances and $49 \%$ of review attendances) and the proportion seen at least once in a paediatric outpatient department in any given year: $8.5 \%$ of children in the age band 0 to 15 years and $12 \cdot 3 \%$ of children under 5 years. These figures are from an extrapolation of the attendance over the 0.71 of a year represented in the Wakefield study period (see table 9). Analysis of monthly attendance shows that there was random variation over the year,

Table 10 Paediatric outpatient study: review attendances by diagnosis based on 2784 attendances in 1630 children

\begin{tabular}{lcc}
\hline Diagnosis & No of attendances & No of children \\
\hline Asthma & 539 & 324 \\
Epilepsy & 237 & 120 \\
Fits* & 130 & 99 \\
Failure to thrive & 120 & 79 \\
Cerebral palsy/mental handicap & 115 & 84 \\
Urinary tract infection & 99 & 73 \\
Soiling/wetting & 88 & 49 \\
Headaches & 79 & 54 \\
Cardiac murmur: & 33 & 31 \\
Organic & 35 & 33 \\
Functional & 68 & 53 \\
Short stature & 65 & 58 \\
Recurrent coughs-not asthma & 60 & 38 \\
Constipation & 54 & 28 \\
Arthritis & 42 & 27 \\
Vomiting & 33 & 20 \\
Chronic diarrhoea & 29 & 21 \\
Delayed development & 26 & 20 \\
Child abuse & 25 & 9 \\
Abdominal pain & 13 & $963(77)$ \\
Behaviour disorder & 12 & \\
Recurrent infections & $1902(68)$ & \\
Total (\%) of all outpatients & & \\
\hline
\end{tabular}

${ }^{*}$ Includes febrile convulsion, apnoea attacks, fits. more dependent on doctors' leave periods than other factors except for an increase in attendance for asthma in November and December.

Previous studies have examined new referrals to paediatricians as part of analysis of multiple specialty outpatient referrals from the general practice perspective. ${ }^{78}$ In East Anglia, an average GP was likely to refer 6.4 children in a year with a $95 \%$ confidence interval of 1 to 12 , representing 0.5 to 6 referrals per thousand per year with a mean of $3 \cdot 2$. This contrasts with the Wakefield study new referral rate per general practice of between 3.7 and 29.6 (mean 13.7) over 0.71 year, equivalent to a mean annual rate of 19.3 per thousand per year. This large difference may be related to the proximity of the population to hospital services. ${ }^{4}$ The Wakefield population is fairly dense urban and semirural in contrast to East Anglia. A large part of the variation in referral rates between individual GPs has not been accounted for and there is a large random effect which is compounded by problems of analysis of small numbers. ${ }^{48}$ Average practice list size is felt to be a better denominator for studies and partially compensates for the small number effect. ${ }^{9} \mathrm{~A}$ further study based on an east Birmingham practice of 11500 people with a new paediatric outpatient referral rate of 4 per thousand children attempted to examine whether the GPs' particular areas of interest may have led to a higher rate of referral and confirmed this to be the case in two of the specialties studied, ${ }^{10}$ although not in paediatrics where no partner has a special interest. These studies have been on new referrals and there appear to be no such data reported elsewhere on review attendance rates in paediatric practice related to population size.

There are very few data available on diagnostic case mix for children attending paediatric outpatient departments. An unpublished study reported in 1989 at the British Paediatric Association annual scientific meeting (CMN Bhrolchain, PW Wilkinson), showed that over a four month period in the Wirral, 374 children were referred as new patients, equivalent to a referral rate of 15.5 per thousand per year; $90 \%$ were from GPs and $12 \%$ from the child health service. Of the patients referred, $30 \%$ were discharged after one consultation $(28 \%$ in the Wakefield study). Asthma was the commonest reason for referral: $12 \cdot 8 \%(11 \cdot 7 \%$ in the Wakefield study see table 3 ) where it was also the commonest reason for attendance as a review patient (see table 10).

This study has shown the scale of paediatric outpatient utilisation in Wakefield. Comparison with HSIs shows that this utilisation was not unusual compared with figures from health authorities in England and Wales. There is a particularly high workload in paediatric outpatients arising from children with asthma. Reduction in hospital attendance may be possible by joint working with GPs especially as a substantial number of the new referrals did not have any test performed. Fewer review attendances for all conditions including asthma, took place from the larger general practices, raising implications for further joint collaboration between consultant paediatricians and GPs. 
Consultant paediatricians saw $44 \%$ of review attendances in this study and had a tendency to see more chronically ill and disabled children. This study has shown the value of diagnostic information in evaluating the use of resources in outpatient clinics.

The authors wish to thank those who made this study possible the consultant and junior medical staff who completed the data orms, Ms Ros Buck, research assistant who entered the data, the District Information Department, Wakefield Health Authority, and Yorkshire Regional Health Authority who financed the project.

1 Royal College of General Practitioners, Office of Population Censuses and Surveys, Department of Health and Social Security. Morbidity statistics from general practice. Third national study 1981-82. London: HMSO, 1986. (Series MB 5 No 1 .
2 Chamberlain RN, Simpson RN. The prevalence of illness in childhood. Report of the British Births Child Study into Ilness and hospital experience of children during the firs 3.5 years of life. London: Pitman Medical, 1979.

3 Dowie R. Patterns of hospital staffing: paediatrics. British Postgraduate Medical Federation.) London: HMSO, 1991.

4 Butler N, Golding J. From birth to six. Oxford: Pergamon Press, 1986.

5 Davie R, Butler N, Goldstein H. From birth to seven. Report of the National Child Development Study (1958 cohort). London: Longman, 1972.

6 Hill AM. Trends in paediatric medical admissions. $B M \mathcal{F}$ 1989;298:1479-83.

7 Moore AT, Roland MO. How much variation in referral rates among general practitioners is due to chance? $B M \mathcal{F} 1989$; 298:500-2.

8 McPherson $\mathrm{K}$. Variations in hospitalisation rates. Why and how to study them. In: Ham C, ed. Variations in health care assessing the evidence. London: Kings Fund Institute 1988.

9 Armstrong D, Britten N, Grace J. Measuring general practitioners referrals: patient workload and list size. $\mathcal{F} R$ Col Gen Pract 1988;38:494-7.

10 Reynolds GA, Chitins JG, Roland MO. General practitione outpatient referrals; do good doctors refer more patients to hospital? BMF 1991;302:1250-2.

\section{Smart from the start}

Babies weren't born yesterday, y'know. Well, let me rephrase that. There is a steadily increasing amount of information showing that quite young babies can take in much more than we used to think they could. There is evidence, for instance, that babies only 2 days old will look at their mother's face in preference to that of a woman unknown to them. A recent article in Nature (P E Bryant, 1991;354:19) reviews some new findings by experimental psychologists. Apparently most babies will look at a checkerboard pattern rather than anything else, even a schematic face. They do, however, prefer a face to most other things but their reactions change as they grow older. Babies under 1 month of age will follow a moving face-like pattern in preference to a 'scrambled' face in which the components are in disarray. If, however, the same experiment is done with the realistic and scrambled faces presented to the baby statically then young babies show no preference but by the age of 2 months they do. In a recent experiment $\mathbf{M} \mathbf{H}$ Johnson and colleagues had an arrangement whereby the babies moved around the patterns. They found that babies up to 1 month preferred to follow a realistic face pattern but older babies had no such preference. P E Bryant suggests that perhaps the older babies just become too smart to continue to be tricked by a pattern which they knew was not a real face. Why very young babies follow a moving face rather than a moving nonface and yet show no preference when the patterns are static is not known. It is suggested that the underlying neurological mechanism involves immaturity of the cortical visual pathways, the preference for a moving face occurring at a time when 'subcortical mechanisms' are important. It is not known, either, whether the preference for moving faces applies to real faces as well as to schematic ones. Whichever way you look at it babies are amazingly perceptive very soon after birth. 